\title{
Fast real time and quantitative gas analysis method for the investigation of the $\mathrm{CO}_{2}$ reduction reaction mechanism
}

\author{
Robin Mutschler, ${ }^{1,2}$ Wen Luo, ${ }^{1,2}$ Emanuele Moioli, ${ }^{1,2}$ and Andreas Züttel ${ }^{1,2}$ \\ ${ }^{1}$ Laboratory of Materials for Renewable Energy (LMER), Institute of Chemical Sciences and Engineering (ISIC), \\ Basic Science Faculty (SB), École Polytechnique Fédérale de Lausanne (EPFL) Valais/Wallis, Energypolis, Sion, \\ Switzerland, Rue de l'Industrie 17, CP 440, CH-1951 Sion, Switzerland \\ ${ }^{2}$ EMPA Materials Science and Technology, CH-8600 Dübendorf, Switzerland
}

(Received 6 July 2018; accepted 1 November 2018; published online 27 November 2018)

\begin{abstract}
We present a new fast real time and quantitative gas analysis method by means of mass spectrometry (MS), which has approximately an order of magnitude faster sampling rate in comparison with a traditional gas chromatography. The method is presented and discussed on the example of the $\mathrm{CO}_{2}$ reduction reaction. The advantages of the method are the possibility to analyze the reaction kinetics, where the kinetically determined reaction range is often only tens of degrees wide. Furthermore, due to the fast sampling rate, the experiments are much shorter and effects due to possible aging of the catalyst are significantly reduced. The quantification of the gas partial pressures is achieved by calibrating the Faraday detector in the quadrupole MS for the expected reactants and products. One major challenge to achieve a quantitative measurement with the MS is to correct for the pressure fluctuations over the probing capillary over the course of the experiment. This fluctuation is compensated in the analysis by normalizing the sum of all calculated partial pressures to the measured reaction pressure for every measured spectrum. With that, a precise, fast, and quantitative gas analysis is achieved. This is the fundament for, e.g., the kinetic reaction analysis where a high data point density is required. The method is discussed on the example of the $\mathrm{CO}_{2}$ hydrogenation reaction to $\mathrm{CH}_{4}$ on a commercial $\mathrm{Ru} / \mathrm{Al}_{2} \mathrm{O}_{3}$ catalyst. Additionally, the key features of the gas controlling and analysis setup built for the $\mathrm{CO}_{2}$ hydrogenation reaction are described. Published by AIP Publishing. https://doi.org/10.1063/1.5047402
\end{abstract}

\section{INTRODUCTION}

The short- and long-term energy storage of renewable energy is one of the major challenges toward an energy supply based on renewable energy converters. Synthesis of hydrocarbons and alcohols from $\mathrm{CO}_{2}$ and $\mathrm{H}_{2}$ is a promising strategy to store renewable energy with a high gravimetrical energy density and for liquid products also with a high volumetric energy density. With the $\mathrm{CO}_{2}$ extracted from air or point sources, the carbon cycle can remain closed with no net $\mathrm{CO}_{2}$ emitted. ${ }^{1}$ The in-depth understanding of the $\mathrm{CO}_{2}$ hydrogenation reaction toward the production of methane, longer chained hydrocarbons, and alcohols is an up-to-date subject of research. ${ }^{2-6}$ Since $\mathrm{CO}_{2}$ is a relatively stable molecule with a standard enthalpy of formation of $\Delta \mathrm{H}_{\mathrm{f}}^{0}=-393.5 \frac{\mathrm{kJ}}{\mathrm{mol}}$, the $\mathrm{CO}_{2}$ hydrogenation reaction requires an efficient catalyst to achieve high activity and selectivity toward desired products. Moreover, the $\mathrm{CO}_{2}$ conversion rate and product selectivity also depend strongly on the reactor design and operation conditions. ${ }^{7,8}$

To investigate the performance of a $\mathrm{CO}_{2}$ hydrogenation catalyst in well-defined conditions, such as pressure, temperature, and gas composition, a gas controlling and analysis experimental setup was developed. Mass spectrometry (MS) and gas chromatography (GC) are the most frequently used detection means for gas analysis. Of which, MS typically serves as a faster detection method even for the unknown products. Although various studies and applications of the quantitative gas analysis using MS have been published, ${ }^{9-11}$ the quantitative product analysis by means of MS for a continuous heterogeneously catalytic reaction, such as the $\mathrm{CO}_{2}$ hydrogenation reaction, was not yet reported. Recently, Alvino et al. demonstrated a quantitative gas analysis method by means of MS via a pressure controlled vacuum chamber. ${ }^{11}$ In their setup, which is equipped with a batch reactor with a sapphire window for photocatalytic experiments, the reaction gas from the reactor was injected into a pressure controlled vacuum chamber with a pulsed nozzle valve. The MS then sampled the gas from the vacuum chamber, which was held at constant pressure for the calibration and the experiments. With this, they achieved quantitative results with high accuracy. In our continuous flow reactors, the reaction conditions such as the pressure and the gas composition can be accurately controlled for the entire duration of the experiment, which is not the case for a batch reactor. Furthermore, the reaction gas is sampled directly from the reaction gas stream and no further parts are required. To account for the pressure fluctuations over the differentially pumped capillary, a new method is presented, which is based on the normalization of the summed up partial pressures of the reaction products to the reaction pressure.

In this work, we constructed a gas controlling and analysis setup for the $\mathrm{CO}_{2}$ hydrogenation reaction investigation, which consists mainly of a gas flow controlling unit for three gases, two reactor ovens, a pressure control unit, and two in-line analysis instruments which are a MS and GC. The GC-MS system are widely used in research for various applications and even played a key role in analyzing the Martian atmosphere during the Viking mission. ${ }^{12}$ The advantages of combined GC-MS 
systems are the high accuracy quantitative product analysis of known and calibrated reactants and products in the GC, coupled with a MS to identify gas traces that either cannot be separated in the GC columns or cannot be identified just based on the peak position and calibration. Anyhow, the drawback of this method is that it is relatively slow. In contrast to the typically used GC-MS systems, the MS and GC are decoupled in this setup, which enables the placement of the MS capillary directly into the reaction gas stream. The benefit of this method is that the gas stream is not yet separated by the GC columns before it is analyzed in the MS. Since a much faster sampling rate is achieved with a standalone MS in comparison with a $\mathrm{GC}$, the reaction gas stream can be sampled with a high resolution in time. Anyhow, to quantify the reaction products, the MS must be calibrated. While the calibration of the GC for gas quantification is a well-known standard procedure, ${ }^{13}$ the calibration of the MS is more challenging because of the following two reasons. First, the MS must be differentially pumped over the sampling capillary for real time gas analysis since a high vacuum is required for the gas ionization and separation in the MS, but the reaction gas stream is at ambient or slightly elevated pressure. Thus, the pressure drop over the capillary will change the absolute intensity of the spectra but maintain the relative intensities. Second, a distinctive mass/charge $(\mathrm{m} / \mathrm{z})$ peak must be selected for each product if possible. If there are overlying peaks, the quantification is only possible by knowing the contribution of a specific gas species to a peak or by knowing the ratios between different peaks of the species.
In this work, we show how to calibrate the MS for selected gases and how to conduct a quantitative reaction analysis based on the MS only. Furthermore, we highlight the advantages of the fast data sampling of the MS in the kinetic reaction analysis.

\section{SETUP LAYOUT AND SPECIFICATIONS}

As illustrated in Fig. 1, the gas controlling and analysis setup was specifically built as a versatile system to study the $\mathrm{CO}_{2}$ hydrogenation reaction using different catalysts and in various reaction conditions. The setup can be operated in a broad temperature $\left(25-800^{\circ} \mathrm{C}\right)$ and pressure ( $0-34$ bars ) range, and the two reactors, which can be switched to serial or single operation mode, are fed with three gases in the flow range of (0.4-20 $\mathrm{ml} / \mathrm{min})$.

The gas controlling unit consists of three mass flow controllers (MFC, Brokhorst El Flow series), two pressure sensors (0-10 bars, 0-100 bars, Keller), and a thermo-controller (Jumo Imago 500). The MFCs are calibrated for $\mathrm{CO}_{2}, \mathrm{He}$, and $\mathrm{H}_{2}$ in a pressure range from 1 to 63 bars and can be operated at gas flows ranging from 0.4 to $20 \mathrm{ml} / \mathrm{min}$. The gas lines after the reactor can be heated up to $220{ }^{\circ} \mathrm{C}$ in order to avoid the condensation of water and liquid products. The Carbolite tubular reactor oven (reactor 1 ) can be heated up to over $800{ }^{\circ} \mathrm{C}$, with a minimum ramping speed of $1{ }^{\circ} \mathrm{C} / \mathrm{min}$. In the second reactor, the minimum heating ramp is $0.1^{\circ} \mathrm{C} / \mathrm{min}$. The second reactor unit consists of a tubular reactor embedded in an aluminum block consisting of two half cylinders to achieve a homogenous

Gas controlling and analysis system FUTURA

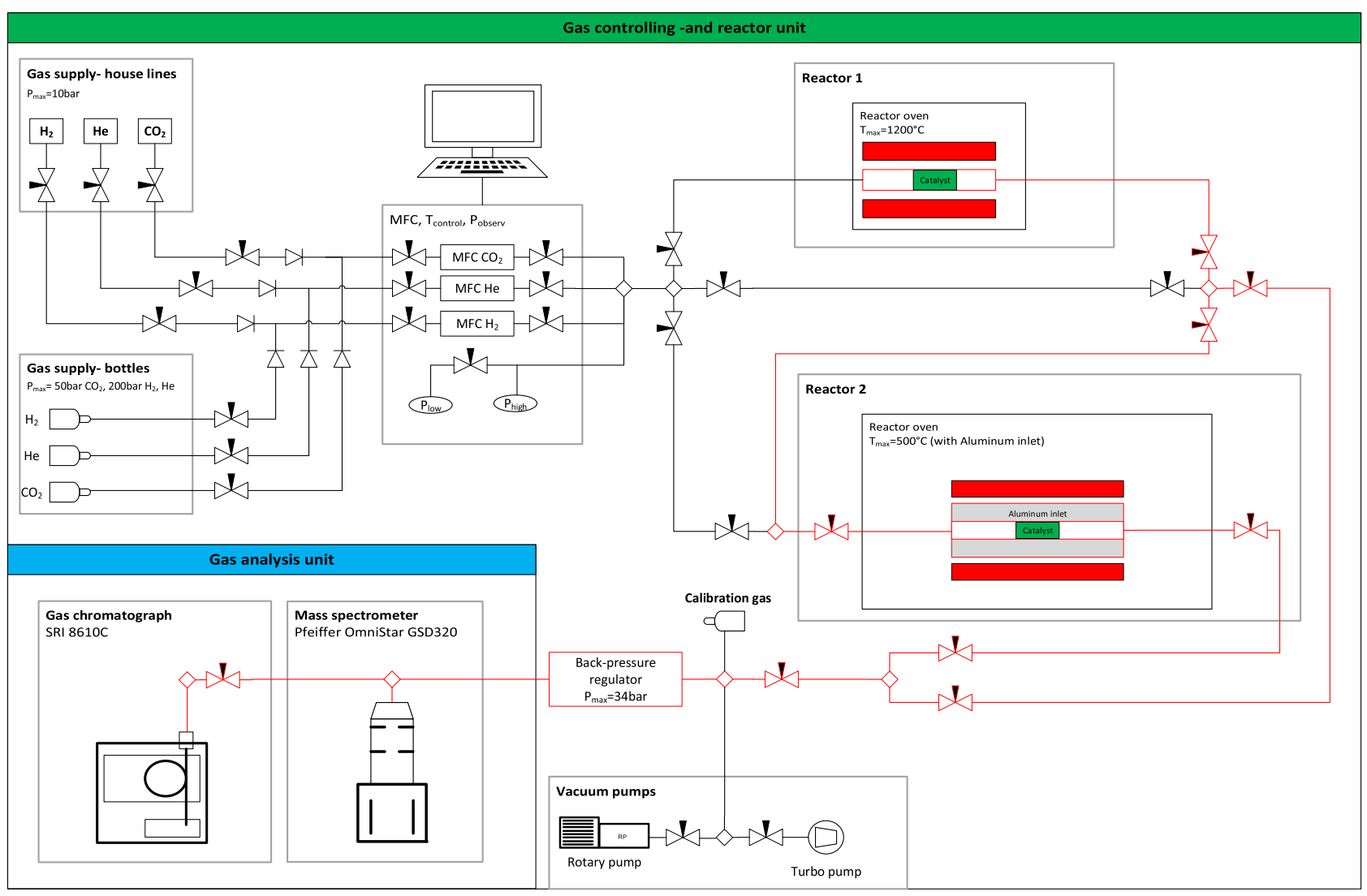

FIG. 1. Schematics of the gas controlling and analysis system. It consists of three main sections, the gas control, reactor, and gas analysis unit. 
temperature distribution in the reactor bed. The aluminum block limits the operation temperature of reactor $2-550{ }^{\circ} \mathrm{C}$ (with a safety margin) since the melting point of $\mathrm{Al}$ is $660{ }^{\circ} \mathrm{C}$. Anyhow, the Al block can also be removed. Therefore, reactor 1 is preferentially used for high temperature reactions, such as the reverse water gas shift reaction, and reactor 2 is used to work in isothermal conditions. Inside each of the ovens a stainless steel tube is installed for the filling of the catalysts (Volume $=0-4 \mathrm{ml}$ ). Moreover, the reactor units can be used in series to investigate two step reactions such as the $\mathrm{CO}_{2}$ hydrogenation to $\mathrm{CO}$ via the RWGS reaction in the first step and then a Fischer-Tropsch like reaction of the $\mathrm{CO}$ (and water) to $\mathrm{C} 2+$ hydrocarbons.

The system is partially controlled (temperatures and gas flows) via a LabVIEW interface. With the thermo-controller, the temperature of the reactor and heating lines after the reactor is monitored. The temperatures, pressures, and gas flows are logged every second with LabVIEW during the experiment for documentation and further analysis. The gas controlling units with the MFCs are all integrated to a modular housing which allows a facile extension of the system with more gas controlling units if required. All tubing and building blocks, such as valves, T-pieces, elbows, etc. (Swagelok), can be heated to $220{ }^{\circ} \mathrm{C}$ or more. A back-pressure valve was used to regulate the pressure between 0 and 34 bars (Swagelok's KPR series).

\section{A. Gas analysis instruments}

The gas analysis is carried out using a GC (SRI 8610C) and a MS (Pfeiffer OmniStar 320 mass spectrometer). The GC is equipped with a Flame Ionization Detector (FID) and Thermal Conductivity Detector (TCD). A $66^{\prime \prime}$ molecular sieve and $6^{\prime \prime}$ silica gel column are used for product separation. He is used as carrier gas. The GC is calibrated for C1-C6 hydrocarbons, $\mathrm{CO}_{2}, \mathrm{CO}$, and $\mathrm{H}_{2}$. The $\mathrm{MS}$ is an integrated system with the vacuum pump, the quadrupole MS, the Faraday and Secondary Electron Detector (SEM), and the heated sampling capillary. Although the SEM detector is, depending on the SEM voltage settings, around three orders of magnitude more sensitive than the Faraday detector, it does not exhibit a linear or reproducible relation to the partial pressures of the gases to be analyzed. Therefore, the Faraday detector is chosen to carry out the quantitative gas analysis in this work, while the SEM can be used for qualitative measurements if a high sensitivity is required (e.g., for the surface reduction of the catalysts).

\section{QUANTITATIVE GAS ANALYSIS USING MS}

The motivation to develop this quantitative gas analysis method by MS was to identify the kinetically determined temperature range of the $\mathrm{CO}_{2}$ hydrogenation over different catalysts which were later found to be around $30 \mathrm{~K}$ wide for the investigated catalysts. The reactor was heated up with $1{ }^{\circ} \mathrm{C} / \mathrm{min}$ and with the $\mathrm{GC}$, and a data point was measured every $17.5 \mathrm{~min}$ (12.5 min sampling time, 5 min cooling time), which is a typical data collecting rate for a GC, thus less than two data points are measured in a temperature range of $30 \mathrm{~K}$. This is not sufficient in any case to identify the kinetically determined temperature range since at least three data points are required for this purpose. One possibility to get more data points in the same temperature range is by reducing the heating rate (which is not possible in every reactor oven and can have a negative effect on the measurement on rapidly aging catalysts), which will extend the duration of the experiment significantly. Therefore, the quantitative gas analysis method by means of MS using the Faraday detector was developed. In the following, the required steps to go from signal to partial gas pressures are discussed and illustrated.

One of the major challenges in the MS calibration is the signal overlap of different ions with the same mass to charge $(\mathrm{m} / \mathrm{z})$ ratio, originating from different molecules. For example, the major peak for $\mathrm{CH}_{4}$ is at $\mathrm{m} / \mathrm{z} 16$, which is also a minor peak for $\mathrm{CO}_{2}$ (whose major peak is at $\mathrm{m} / \mathrm{z} 44$ ). Therefore, if the gas contains both $\mathrm{CH}_{4}$ and $\mathrm{CO}_{2}$, the gases cannot be quantified using the $\mathrm{m} / \mathrm{z} 16$ peak without further information. Since peak intensity ratios between the major and minor peaks of a gas molecular can also be obtained from MS, the contribution of $\mathrm{CO}_{2}$ to the $\mathrm{m} / \mathrm{z} 16$ peak can be calculated based on the peak intensity of the $\mathrm{m} / \mathrm{z} 44$ peak. Therefore, if, e.g., $\mathrm{CH}_{4}$ is calibrated using the $\mathrm{m} / \mathrm{z} 16$ peak and $\mathrm{CO}_{2}$ is present in the gas mixture, the sole contribution of $\mathrm{CH}_{4}$ to the $\mathrm{m} / \mathrm{z}$ 16 peak can be calculated as discussed later in more detail. Another major challenge is the pressure drop over the capillary, which influences the amount of gas being introduced into the capillary and therefore the signal intensity of the contained molecules. However, since the ratios between the gas species are not influenced and the sum of all partial pressures in the gas mixture can be normalized with the measured total reaction pressure at each measurement point, the partial pressure of each gas species can then be calculated for each measured spectrum.

\section{A. Calibration of the MS}

The capillary of the MS is directly placed in the product gas stream, and the gas sample is induced through the capillary to the filament by differential pumping. On the filament, the gas molecules are ionized and then separated in the quadrupole based on their mass to charge ratio. The incident ions on the Faraday cup detector create a signal proportional to their quantity and occurrence frequency. Therefore, to calibrate the MS, gas mixtures with known partial pressures are required.

In the following, the calibration, the peak ratio determination, and pressure normalization are discussed. The MS is calibrated with three different sets of gas mixtures. In each set, the gases are mixed at different ratios to obtain the signal strength at selected peaks (ion current) at different partial gas pressures. The three sets of calibration spectra are obtained

TABLE I. Gas composition for the calibration spectra of the MS.

\begin{tabular}{lccc}
\hline \hline Spectra & $\mathrm{He}(\%)$ & $\mathrm{CH}_{4}(\%)$ & $\mathrm{CO}_{2}(\%)$ \\
\hline$\# 1$ & 90 & 05 & 05 \\
$\# 2$ & 15 & 10 & 75 \\
$\# 3$ & 50 & 25 & 25 \\
$\# 4$ & 20 & 40 & 40 \\
$\# 5$ & 15 & 75 & 10 \\
\hline \hline
\end{tabular}




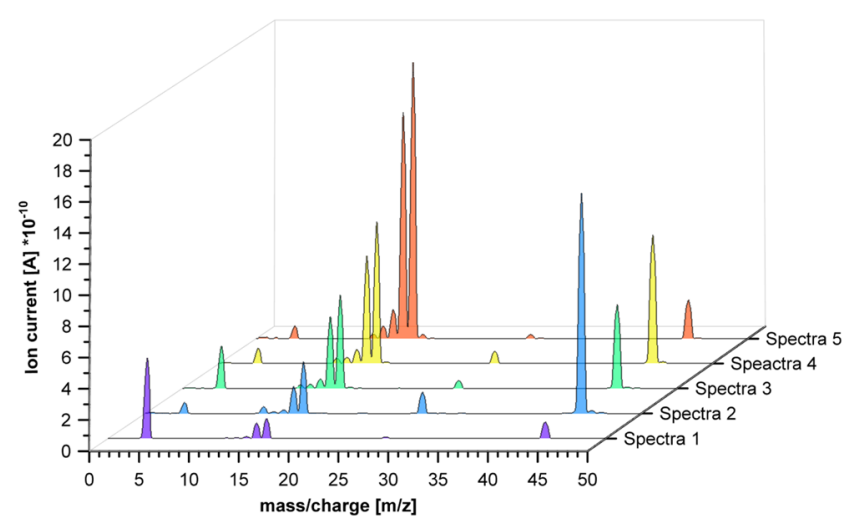

FIG. 2. The MS spectra of the gas mixtures given in Table I.

TABLE II. The peak correlation coefficients calculated for the specific masses with the three calibration spectra sets.

\begin{tabular}{lcccc}
\hline \hline Gas & $\begin{array}{c}\text { Calibration } \\
\text { spectra set }\end{array}$ & $\mathrm{m} / \mathrm{z}$ & $\begin{array}{c}\text { Correlation coefficient a } \\
\mathrm{p}_{\mathrm{i}}=\mathrm{a} * \mathrm{~A}_{\text {peak }}\end{array}$ & $\mathrm{R}^{2}$ \\
\hline $\mathrm{H}_{2}$ & 1 & 2 & $4.205 \times 10^{9}$ & 0.951 \\
$\mathrm{CO}_{2}$ & 1 & 44 & $2.622 \times 10^{9}$ & 0.994 \\
$\mathrm{CO}_{2}$ & 1 & 28 & $2.983 \times 10^{10}$ & 0.999 \\
$\mathrm{CO}_{2}$ & 1 & 16 & $3.374 \times 10^{10}$ & 0.998 \\
$\mathrm{He}$ & 2 & 4 & $1.010 \times 10^{10}$ & 0.995 \\
$\mathrm{CH}$ & 2 & 15 & $2.902 \times 10^{9}$ & 0.996 \\
$\mathrm{CO}$ & 3 & 28 & $1.256 \times 10^{9}$ & 0.990 \\
\hline \hline
\end{tabular}

from three gas mixtures including (1) $\mathrm{H}_{2}, \mathrm{He}$, and $\mathrm{CO}_{2}$; (2) $\mathrm{He}, \mathrm{CH}_{4}$, and $\mathrm{CO}_{2}$; and (3) $\mathrm{CO}, \mathrm{CO}_{2}$, and $\mathrm{He}$ gas mixture. For the calibration of $\mathrm{H}_{2}, \mathrm{He}, \mathrm{CH}_{4}, \mathrm{CO}$, and $\mathrm{CO}_{2}, \mathrm{~m} / \mathrm{z}$ of $2,4,15$, 28 , and 44 is used, respectively. The compositions of the first calibration spectra set are given in Table I. Figure 2 shows the overlaid spectra of the five different gas mixtures for the first calibration spectra set.

To calibrate the MS for different gases, the peak areas are integrated with the trapezoidal numerical integration method "trapz" in MATLAB R2016b. The integration width is chosen to be $1 \mathrm{~m} / \mathrm{z}$, e.g., to calculate the peak area of the peak at $\mathrm{m} / \mathrm{z} 15$, the peak area is integrated between $\mathrm{m} / \mathrm{z} 14.5$ and $\mathrm{m} / \mathrm{z} 15.5$. The integrated peak area $\left(\mathrm{A}_{\text {peak }}\right)$ is then correlated with each partial pressure of the gas $\left(\mathrm{p}_{\mathrm{i}}\right)$, and a linear curve is fitted through the calibration points to obtain the calibration parameter (a) to calculate the partial gas pressure from the peak area with the following equation:

$$
\mathrm{p}_{\mathrm{i}}=\mathrm{a} * \mathrm{~A}_{\text {peak }} .
$$

The calibration results obtained from linear regressions through the calibration points (ion current vs. partial gas pressure) are summarized in Table II.

\section{Partial pressure determination on an overlapping peak}

In Sec. III A, the peak calibration for non-overlapping peaks was discussed. Here we discuss how to handle overlapping peaks and how the partial pressure of gas specie can be calculated by using calibrated peaks and peak ratios on the example of $\mathrm{m} / \mathrm{z} 16$ which has contributions from $\mathrm{CH}_{4}$ and $\mathrm{CO}_{2}$ in the case that those two gases are present in the gas mixture simultaneously. From the calibration of the MS for $\mathrm{CO}_{2}$, the peak ratios between the major peak at $\mathrm{m} / \mathrm{z} 44$ and three minor peaks at $\mathrm{m} / \mathrm{z} 12, \mathrm{~m} / \mathrm{z} 16$, and $\mathrm{m} / \mathrm{z} 28$ are known and illustrated in Fig. 3 and are summarized in Table III. The ratio between $\mathrm{m} / \mathrm{z} 44$ and $\mathrm{m} / \mathrm{z} 16$ is 13.4 with a standard deviation of 0.7 . The calibration spectra set shown in Fig. 2 is now used to demonstrate how the partial pressure of $\mathrm{CH}_{4}$ is calculated with the peak on $\mathrm{m} / \mathrm{z} 16$.

The contribution of $\mathrm{CO}_{2}$ to $\mathrm{m} / \mathrm{z} 16$ is calculated using the determined peak ratio $\mathrm{R}_{44 t o 16, \mathrm{CO}_{2}}$,

$$
\mathrm{A}_{\mathrm{mz} 16, \mathrm{CO}_{2}}=\frac{\mathrm{A}_{\mathrm{mz} 44}}{\mathrm{R}_{44 \text { to16,CO}}} .
$$

The contribution of $\mathrm{CH}_{4}$ to $\mathrm{m} / \mathrm{z} 16$ is then given by

$$
\mathrm{A}_{\mathrm{mz} 16, \mathrm{CH}_{4}}=\mathrm{A}_{\mathrm{mz} 16}-\mathrm{A}_{\mathrm{mz} 16, \mathrm{CO}_{2}} \text {. }
$$

With that, the peak ratio between m/z 15 and m/z 16 for $\mathrm{CH}_{4}$ is determined,

$$
\mathrm{R}_{16 \text { to15, } \mathrm{CH}_{4}}=\frac{\mathrm{A}_{\mathrm{mz} 16, \mathrm{CH}_{4}}}{\mathrm{~A}_{\mathrm{mz} 15, \mathrm{CH}_{4}}} .
$$

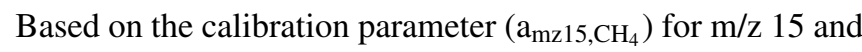
the peak ratio of $\mathrm{CH}_{4}$ for $\mathrm{m} / \mathrm{z} 16$ and $\mathrm{m} / \mathrm{z} 15$, the partial pressure

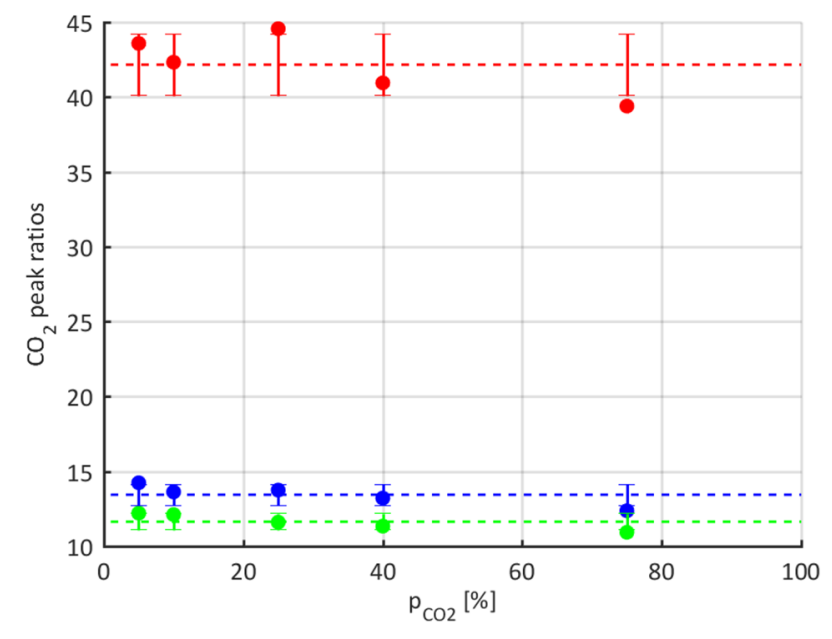

FIG. 3. Peak ratios between different $\mathrm{m} / \mathrm{z}$ of $\mathrm{CO}_{2}$. The calculated standard deviations are indicated with the error bars and the dotted lines show the mean value. 
TABLE III. Peak ratios between different $\mathrm{m} / \mathrm{z}$ of $\mathrm{CO}_{2}$.

\begin{tabular}{lcc}
\hline \hline Ratio between $\mathrm{m} / \mathrm{z}$ 's & Ratio & Standard deviation from mean value \\
\hline 44 to 28 & 11.6 & 0.5 \\
44 to 16 & 13.4 & 0.7 \\
44 to 12 & 42.2 & 2.1 \\
\hline \hline
\end{tabular}

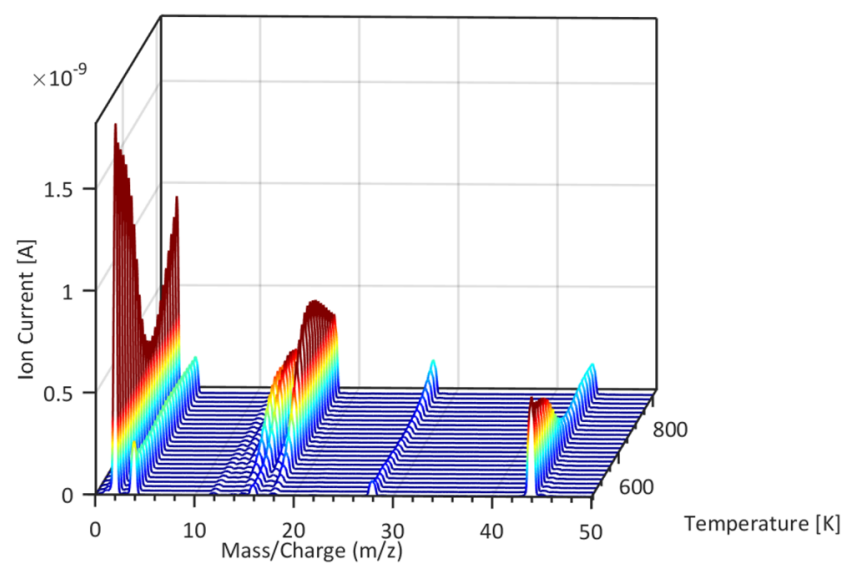

FIG. 4. Plot of the MS spectra (reduced number of spectra from 300 to 40 for better visibility) of the $\mathrm{CO}_{2}$ hydrogenation over a $0.5 \mathrm{wt}$. \% Ru on $\mathrm{Al}_{2} \mathrm{O}_{3}$ catalyst as a function of reaction temperature. $\mathrm{m} / \mathrm{z} 44$ is the main $\mathrm{CO}_{2}$ peak. $\mathrm{m} / \mathrm{z} 28$ is a minor $\mathrm{CO}_{2}$ peak and the major $\mathrm{CO}$ peak. The signal at $\mathrm{m} / \mathrm{z} 18$ and $\mathrm{m} / \mathrm{z} 17$ is due to the water formed in the Sabatier reaction. $\mathrm{m} / \mathrm{z} 16$ and m/z 15 are the major peaks of $\mathrm{CH}_{4} \cdot \mathrm{m} / \mathrm{z} 16$ also has a small contribution of $\mathrm{CO}_{2} \cdot \mathrm{m} / \mathrm{z}$ 4 is $\mathrm{He}$ and $\mathrm{m} / \mathrm{z} 2$ is $\mathrm{H}_{2}$.

of $\mathrm{CH}_{4}$ in the gas mixture is calculated,

$$
\mathrm{p}_{\mathrm{CH}_{4}}=\mathrm{a}_{\mathrm{mz} 15, \mathrm{CH}_{4}} * \frac{\mathrm{A}_{\mathrm{mz} 16, \mathrm{CH}_{4}}}{\mathrm{R}_{16 \mathrm{to} 15, \mathrm{CH}_{4}}} .
$$

With this method the partial pressure of $\mathrm{CH}_{4}$ in the gas mixture is calculated with high accuracy. Furthermore, a possibility on how to handle overlapping peaks is demonstrated.

\section{Quantitative gas analysis in a $\mathrm{CO}_{2}$ hydrogenation reaction}

In this section, the determination of the partial pressures in a real experiment is discussed. As stated above, the differential pressure over the MS capillary leads to deviations in the signal intensity. This is likely to occur over the course of a long-term experiment. In the following, the $\mathrm{CO}_{2}$ hydrogenation reaction over a commercially available $\mathrm{Ru} / \mathrm{Al}_{2} \mathrm{O}_{3}$ catalyst (with 0.5 wt. \% Ru loading, Sigma Aldrich 206199) is analyzed and reaction kinetic is determined by analyzing the gas products using MS.

The catalyst $(0.194 \mathrm{mg})$ is pre-reduced in a $\mathrm{H}_{2}$ $(7.5 \mathrm{ml} / \mathrm{min})$ and $\mathrm{He}(2.5 \mathrm{ml} / \mathrm{min})$ mixture flow at the temperature range from 150 to $540{ }^{\circ} \mathrm{C}$ (at $7^{\circ} \mathrm{C} / \mathrm{min}$ ), and the oven is kept at $540{ }^{\circ} \mathrm{C}$ until the water signal declines to a minimum level. After cooling the reactor down to $150{ }^{\circ} \mathrm{C}$, the reaction gas flow is introduced to the reactor $\left(\mathrm{H}_{2}\right.$ to $\mathrm{CO}_{2}$ ratio of $4: 1$ with $\mathrm{He}$ as carrier gas). The total applied flow is $10 \mathrm{ml} / \mathrm{min}$ at ambient pressure and is composed of $15 \% \mathrm{CO}_{2}, 60 \% \mathrm{H}_{2}$, and $25 \% \mathrm{He}$. The reactor is then heated from $150{ }^{\circ} \mathrm{C}$ to $540^{\circ} \mathrm{C}$ with an effective ramping rate of $0.7^{\circ} \mathrm{C} / \mathrm{min}$ and a total experimental time of $550 \mathrm{~min}$. In total, 284 spectra were collected over the course of the experiment using the MS, and each spectrum takes $116 \mathrm{~s}$ which corresponds to an approximate temperature range of $1.4^{\circ} \mathrm{C}$. Note here that the scan width is from 1 to $100 \mathrm{~m} / \mathrm{z}\left(1 \mathrm{~m} / \mathrm{z} \mathrm{s}^{-1}\right)$, the extra $6 \mathrm{~s}$ per spectra come from the time the instrument requires to process the data before measuring the next spectrum. Simultaneously GC spectra were collected every $17.5 \mathrm{~min}$, which corresponds to an approximate temperature resolution of $12.3^{\circ} \mathrm{C}$. Therefore, the MS acquires spectra more than 9 times faster than the GC. By increasing the scan speed in the MS from $1 \mathrm{~s} / \mathrm{mass}$ to $200 \mathrm{~ms} / \mathrm{mass}$, the spectra amount difference between MS and GC can be increased by a factor of five to 45 .

The MS spectra over the course of the experiment are plotted as a function of temperature in Fig. 4. For better

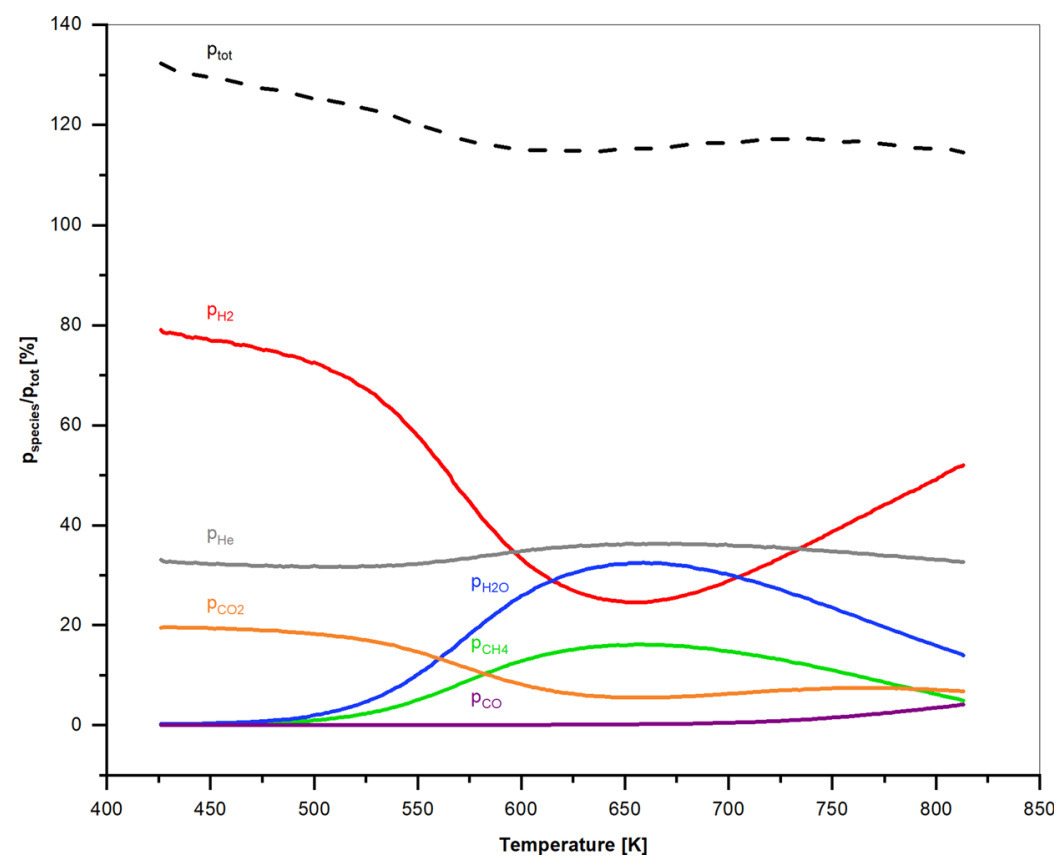

FIG. 5. The sum of the individual partial pressures does not equal the total reaction pressure. 


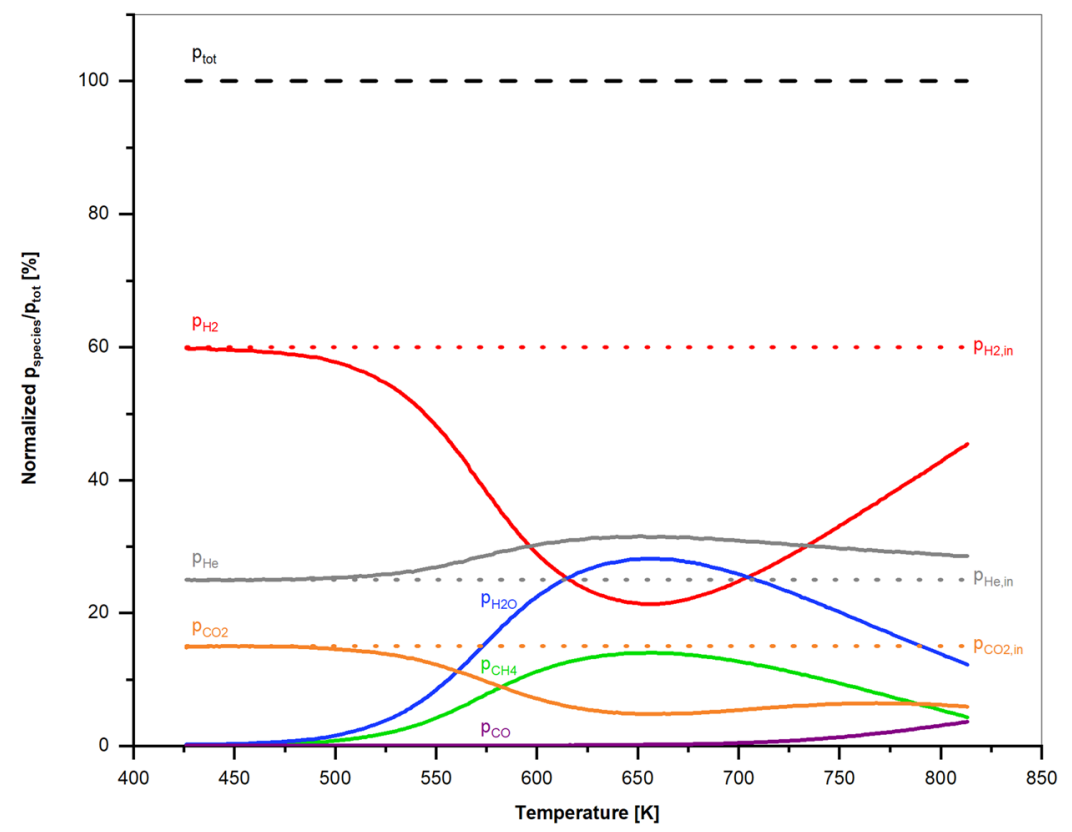

FIG. 6. Normalized conversion curve. The sum of all partial pressures of all gas detected gas species is normalized to the total pressure.

visibility, the number of spectra was reduced to 40 in the plot. As shown in Fig. 4, $\mathrm{CO}, \mathrm{CH}_{4}$, and $\mathrm{H}_{2} \mathrm{O}$ are detected in the product gas stream, therefore, it can be concluded that the Sabatier and Reverse Water Gas Shift (RWGS) reaction are occurring simultaneously to different extents at different temperatures.

The Sabatier reaction is defined as

$$
\mathrm{p}_{\mathrm{CO}_{2}}+4 \mathrm{p}_{\mathrm{H}_{2}} \rightleftharpoons \mathrm{p}_{\mathrm{CH}_{4}}+2 \mathrm{p}_{\mathrm{H}_{2} \mathrm{O}} .
$$

And the RWGS is

$$
\mathrm{p}_{\mathrm{CO}_{2}}+\mathrm{p}_{\mathrm{H}_{2}} \rightleftharpoons \mathrm{p}_{\mathrm{CO}}+\mathrm{p}_{\mathrm{H}_{2} \mathrm{O}} .
$$

Since the MS is not calibrated for water vapor, the partial pressure of water is defined based on the reaction stoichiometry of the Sabatier and RWGS reaction. In the Sabatier reaction, 2 mol of water are formed for every mole of $\mathrm{CH}_{4}$, and in the RWGS, $1 \mathrm{~mol}$ of water is formed for every mole of CO. Therefore, the partial pressure of water is defined as

$$
\mathrm{p}_{\mathrm{H}_{2} \mathrm{O}}=\mathrm{p}_{\mathrm{CO}}+2 * \mathrm{p}_{\mathrm{CH}_{4}} .
$$

With this definition and the calibration for the other gas species, the partial pressure of the reactant and product gas species is calculated at each temperature. The total pressure $\mathrm{p}_{\text {tot }}$ of the gas is the sum of all partial pressures $p_{i}$,

$$
\sum_{\mathrm{i}} \mathrm{p}_{\mathrm{i}}=\mathrm{p}_{\mathrm{tot}} .
$$

Figure 5 shows the calculated partial pressures of reactants and products and the summed up total pressure of the partial pressures in each point in relation to the known (measured) reaction pressure, which in this case is 1 bar. It can be seen

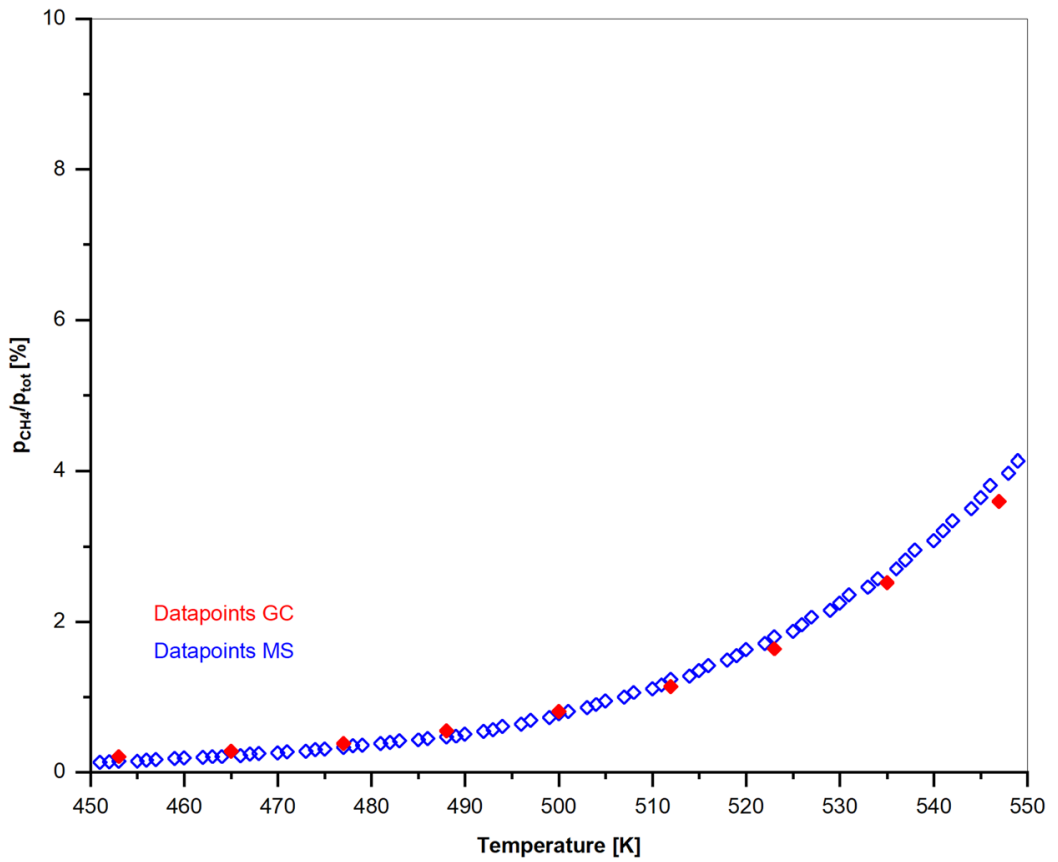

FIG. 7. Comparison of data point density for the partial pressure of $\mathrm{CH}_{4}$ between $\mathrm{GC}$ and MS in the low temperature region where the reaction is kinetically determined. A nine times higher data point density/temperature is achieved with the MS with a scanwidth of $100 \mathrm{~m} / \mathrm{z}$ and an integration time of $1 \mathrm{~s}$ per $\mathrm{m} / \mathrm{z}$. 
that the calculated $p_{\text {tot }}$ varies over the course of the experiment even though the reaction pressure is kept constant at 1 bar.

But since the total reaction pressure is known and the ratio between the partial pressures is independent of the pressure drop over the capillary, the sum of the calculated partial pressures can be normalized on the known total reaction pressure,

$$
\mathrm{p}_{\mathrm{i}, \text { norm }}=\mathrm{p}_{\mathrm{i}} * \frac{\mathrm{p}_{\text {reaction }}}{\mathrm{p}_{\text {tot }}},
$$

where $p_{i, n o r m}$ is the sum of all calculated partial pressures normalized to the measured reaction pressure preaction $_{\text {. }}$
With that, the partial pressure of each reactant and product gas species is accurately determined in each measurement point (Fig. 6). The known reactant partial pressures are plotted as a reference.

The accurate determination of the partial reaction pressures is fundamental for the further data analysis, for instance, the $\mathrm{CO}_{2}$ conversion $\mathrm{X}_{\mathrm{CO}_{2}}$, the product yield $\mathrm{Y}_{\mathrm{P}}$, and the selectivity $\mathrm{S}_{\mathrm{P} .} \mathrm{X}_{\mathrm{CO}_{2}}$ is calculated based on the partial pressure of $\mathrm{CO}_{2}$ in the product gas stream, $\mathrm{p}_{\mathrm{CO}_{2}, \mathrm{o}}$, and the sum of the partial pressures of the carbon containing reaction products $\mathrm{p}_{\mathrm{P}}$, in this case,

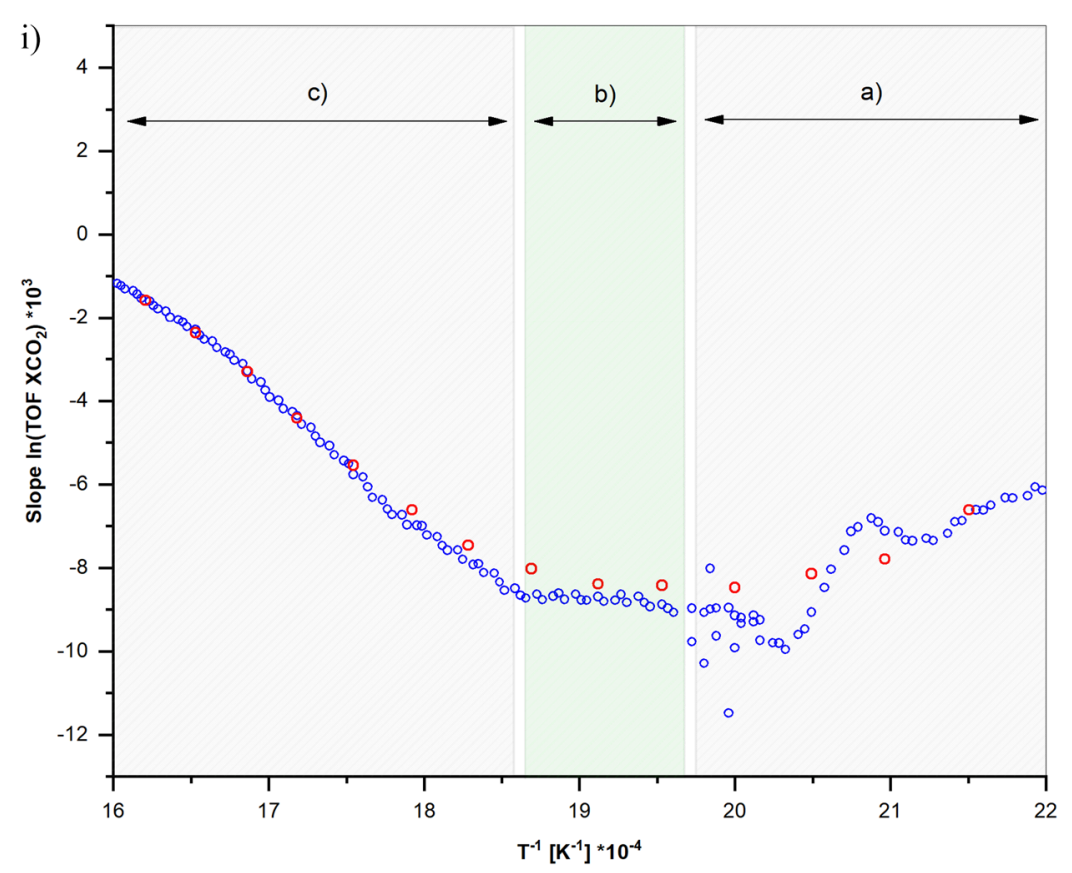

- MS datapoints $\circ$ GC datapoints

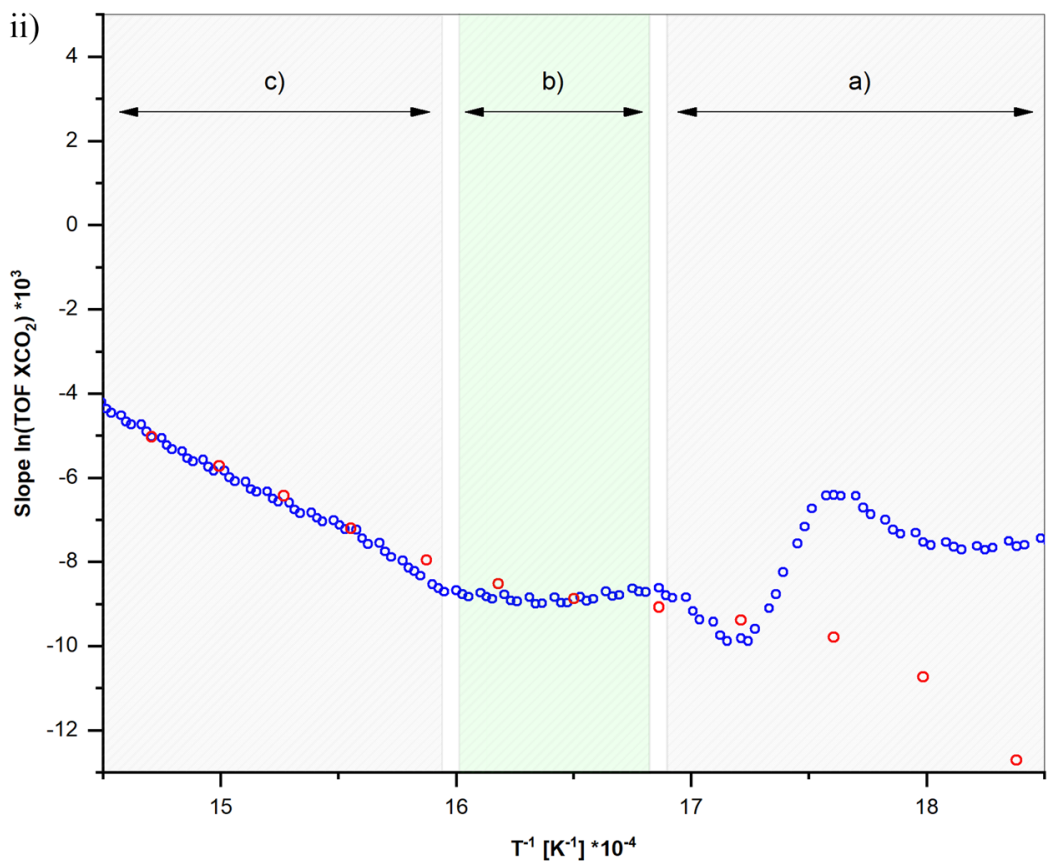

FIG. 8. Identification of the kinetically determined temperature range based on the MS and GC data. (i) is the described $\mathrm{Ru} / \mathrm{Al}_{2} \mathrm{O}_{3}$ catalyst, and (ii) is a Ni catalyst also active in the $\mathrm{CO}_{2}$ hydrogenation reaction. The kinetic temperature range (b) is approximatively $510-540 \mathrm{~K}$ in (i) and $600-630 \mathrm{~K}$ in (ii). The low conversion range (a) is predominated by noise. At higher temperatures, range (c), the reaction is limited by factors such as diffusion and thermodynamics. 


$$
\begin{gathered}
\mathrm{p}_{\mathrm{P}}=\mathrm{p}_{\mathrm{CH}_{4}}+\mathrm{p}_{\mathrm{CO}}, \\
\mathrm{X}_{\mathrm{CO}_{2}}=\frac{\mathrm{p}_{\mathrm{P}}}{\mathrm{p}_{\mathrm{P}}+\mathrm{p}_{\mathrm{CO}_{2}, \mathrm{o}}}=1-\frac{\mathrm{p}_{\mathrm{CO}_{2}, \mathrm{o}}}{\mathrm{p}_{\mathrm{P}}+\mathrm{p}_{\mathrm{CO}_{2}, \mathrm{o}}} .
\end{gathered}
$$

From the $\mathrm{CO}_{2}$ conversion, $\mathrm{Y}_{\mathrm{p}}$ and $\mathrm{S}_{\mathrm{p}}$ for a specific gas can be directly calculated, e.g., for $\mathrm{CH}_{4}$,

$$
\mathrm{Y}_{\mathrm{CH}_{4}}=\mathrm{X}_{\mathrm{CO}_{2}} * \frac{\mathrm{p}_{\mathrm{CH}_{4}}}{\mathrm{p}_{\mathrm{P}}}=\mathrm{X}_{\mathrm{CO}_{2}} * \mathrm{~S}_{\mathrm{CH}_{4}} \text {, }
$$

with

$$
\mathrm{S}_{\mathrm{CH}_{4}}=\frac{\mathrm{p}_{\mathrm{CH}_{4}}}{\mathrm{p}_{\mathrm{P}}} .
$$

Also, the reaction kinetics can be analyzed, which was the original motivation when developing this fast sampling method. Figure 7 shows the comparison between the MS and GC data point density for the same experiment. The MS data plot follows well with that of the GC, which confirms the validation of this quantitative gas analysis method and moreover, the MS plot shows a much higher data density in comparison with GC.

One key parameter to describe the kinetics of a reaction over a catalyst is the activation energy. The Arrhenius equation (15) relates the rate constant $\mathrm{k}(\mathrm{T})$ with the activation energy $E_{a}$, a constant, and the reaction temperature T. $\mathrm{k}_{0}$ is the pre-exponential factor of the Arrhenius equation.

Arrhenius equation:

$$
\mathrm{k}(\mathrm{T})=\mathrm{k}_{0} \exp \left(-\frac{\mathrm{Ea}}{\mathrm{RT}}\right) .
$$

The activation energy is a kinetic reaction parameter and has to be calculated in the kinetically determined reaction range. For the Sabatier reaction, this range is at low reaction temperatures where the thermodynamic limitation on the reaction is still limited. (At $450 \mathrm{~K}$ and a reaction pressure of $1 \mathrm{bar}$, the maximum conversion allowed by thermodynamics is above $99 \%$, at $550 \mathrm{~K}$ still above $96 \%$.) To identify the kinetically determined reaction range, the Arrhenius equation is rearranged to

$$
\ln (\mathrm{k}(\mathrm{T}))=\ln \left(\mathrm{k}_{0}\right)-\frac{\mathrm{Ea}}{\mathrm{R}} * \frac{1}{\mathrm{~T}} .
$$

In a plot of $\ln (\mathrm{k}(\mathrm{T}))$ vs. $\frac{1}{\mathrm{~T}}$, the curve has a slope of $-\frac{\mathrm{Ea}}{\mathrm{R}}$ and a $\mathrm{y}$-axis intercept of $\ln \left(\mathrm{k}_{0}\right)$ and is called the Arrhenius plot. The slope of the curve in the Arrhenius plot is directly proportional to $\mathrm{E}_{\mathrm{a}}$. The kinetically determined reaction temperature range can be found if the slope of $\ln (k(T))$, which is the Turnover Frequency (TOF) of the $\mathrm{CO}_{2}$ conversion (the calculation of the TOF is given in the supplementary material), is plotted against the inverse temperature. The kinetic range is where the slope of this curve is constant (Fig. 8). It can be seen in Fig. 8(i), that the kinetic reaction range can be determined with the GC in some cases, but that the identification is not possible with confidence in other cases as shown in Fig. 8(ii), where the linear slope - and therefore the kinetically determined reaction range-is clearly identified with the MS data points but not with the GC data points. The larger data point density provides a higher confidence in selecting the right temperature range for the Arrhenius plot in any case, in particular, for catalysts that do not have such a broad kinetically determined reaction range or where the change in slope is not sufficient to be identified with the slower sampling GC.

\section{CONCLUSION}

A quantitative gas analysis method by means of mass spectrometry and the required calibration method, as well as the complete instrumental setup to study the $\mathrm{CO}_{2}$ hydrogenation reaction in the gas phase, was presented in this paper. The quantitative analysis by means of MS enables rapid sampling of the product gas stream providing a significantly higher data point density in comparison with a traditional GC. This enables a kinetic reaction analysis with high confidence and furthermore, a significant reduction in the experiment time, which is crucial for the investigation of fast aging catalysts.

\section{SUPPLEMENTARY MATERIAL}

See supplementary material for the characterization of the $\mathrm{Ru} / \mathrm{Al}_{2} \mathrm{O}_{3}$ catalyst and the calculation of the Turnover Frequency (TOF).

\section{ACKNOWLEDGMENTS}

Financial support by the Swiss National Science Foundation Project "Investigation and modeling of new $\mathrm{CO} 2$ adsorption materials and their interaction with hydrogen" Verfügung 200021_163010/1 and the SCCER Heat \& Electricity Storage (Innosuisse) are acknowledged. We furthermore thank David Lopin for his work on the electronic control system of the setup. Stéphane Voeffray is acknowledged for the construction of the reactors. We also thank Dr. Laure Menin and Dr. Luc Patiny from the Mass Spectrometry facility at EPFL for their constructive inputs and discussions.

\footnotetext{
${ }^{1}$ A. Züttel, P. Mauron, S. Kato, E. Callini, M. Holzer, and J. Huang, CHIMIA Int. J. Chem. 69, 264-268 (2015).

${ }^{2}$ X. Lim, Nature 526, 628 (2015).

${ }^{3}$ P. Gao, S. Li, X. Bu, S. Dang, Z. Liu, H. Wang, L. Zhong, M. Qiu, C. Yang, J. Cai, W. Wei, and Y. Sun, Nat. Chem. 9, 1019-1024 (2017).

${ }^{4}$ J. Wei, Q. Ge, R. Yao, Z. Wen, C. Fang, L. Guo, H. Xu, and J. Sun, Nat. Commun. 8, 15174 (2017).

${ }^{5}$ W. Wang, S. Wang, X. Ma, and J. Gong, Chem. Soc. Rev. 40, 3703-3727 (2011).

${ }^{6}$ Y. Li, S. H. Chan, and Q. Sun, Nanoscale 7, 8663-8683 (2015).

${ }^{7}$ M. D. Porosoff, B. Yan, and J. G. Chen, Energy Environ. Sci. 9, 62-73 (2016).

${ }^{8}$ S. Kattel, P. Liu, and J. G. Chen, J. Am. Chem. Soc. 139, 9739-9754 (2017).

${ }^{9}$ M. Roos, S. Kielbassa, C. Schirling, T. Häring, J. Bansmann, and R. J. Behm, Rev. Sci. Instrum. 78, 084104 (2007).

${ }^{10}$ R. E. Ellefson, D. Cain, and C. N. Lindsay, J. Vac. Sci. Technol., A 5, 134-139 (1987).

${ }^{11}$ J. F. Alvino, T. Bennett, R. Kler, R. J. Hudson, J. Aupoil, T. Nann, V. B. Golovko, G. G. Andersson, and G. F. Metha, Rev. Sci. Instrum. 88, 054101 (2017).

${ }^{12}$ D. R. Rushneck, A. V. Diaz, D. W. Howarth, J. Rampacek, K. W. Olson, W. D. Dencker, P. Smith, L. McDavid, A. Tomassian, M. Harris, K. Bulota, K. Biemann, A. L. LaFleur, J. E. Biller, and T. Owen, Rev. Sci. Instrum. 49, 817-834 (1978)

${ }^{13}$ G. Guiochon and C. L. Guillemin, Rev. Sci. Instrum. 61, 3317-3339 (1990).
} 